\title{
Emeritus Professor Chia Boon Lock (1939-2017): Doyen of cardiology
}

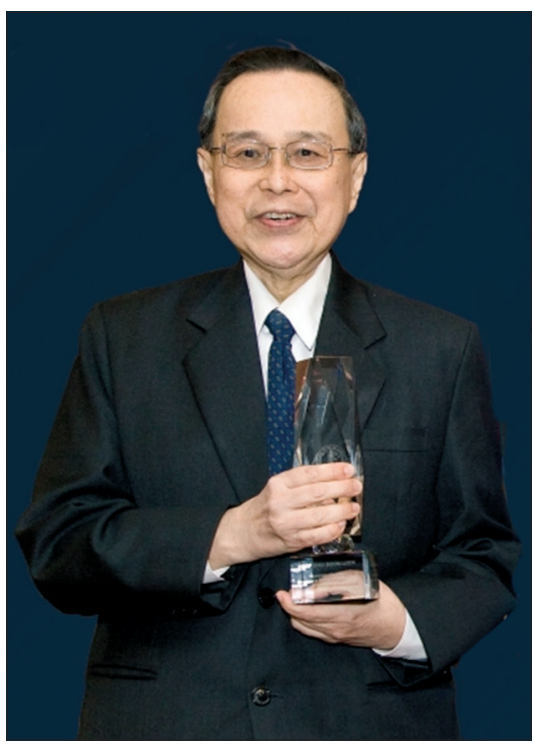

Prof Chia Boon Lock, Emeritus Professor of Medicine at the Yong Loo Lin School of Medicine, National University of Singapore (NUS), Singapore, passed away peacefully at home on 27 December 2017 at the age of 78 years.

Prof Chia, an early pioneer in cardiology, joined NUS as a senior lecturer in medicine in 1972 and was promoted to full professor in 1981. He was in charge of cardiology in Medical Unit II at the Singapore General Hospital (SGH) from 1975 to 1985 and was also head of the department from 1981 to 1983 . He then went to the National University Hospital, becoming head of the hospital's Division of Cardiology, Department of Medicine, from 1986 to 1989 and chief of the Cardiac Department from 1996 to 1999. In 2006, he was conferred the title of Emeritus Professor by NUS.

\section{FIVE DECADES OF CARDIOLOGY}

Prof Chia devoted his five-decade career to medicine despite his multiple talents, including music and the English language, and was a witness, participant and champion of many changes in cardiology practice in Singapore. In 1963, Prof Chia graduated from the University of Singapore medical school and travelled to Sydney in 1968 on a Colombo Plan scholarship to train as a fellow in cardiology. At that time, the care of patients with acute myocardial infarction was primitive and basically consisted of five weeks of bed rest.(1) He was involved in setting up the first modern coronary care unit and coronary care ambulance in SGH in 1973, and was the first to introduce M-mode echocardiography in 1976. Prof Chia had a sabbatical in 1979 at the Division of Cardiology, Stanford University Medical Centre, in Stanford, California, USA, where he trained in echocardiography and coronary angiography, and he pioneered the use of two-dimensional echocardiography in Singapore two years later. Although he had received no formal training in hypertension and lipid management, he soon became a giant in these fields and was a key opinion leader in Southeast Asia. In Singapore, he was the first to introduce ambulatory blood pressure monitoring in 1986 and was involved in various Ministry of Health workgroups for its clinical practice guidelines (CPGs) on lipids and hypertension. He was the chairman of the workgroup for the first and second CPGs on lipids, which spanned more than a decade, and was the adviser for the third and most current guidelines. ${ }^{(2)}$

Despite his contributions to numerous other areas, Prof Chia's greatest love and passion was the field of electrocardiography (ECG). While his peers collected fine wine and rare stamps, Prof Chia collected electrocardiograms. His book Clinical Electrocardiography (4th edition, 2015), a labour of love that he revised in his twilight years, is the bible of local cardiologists and medical students for ECG. As Dr Peter Yan wrote in his review of his book, it "is a must-read that can turn a novice into a competent ECG interpreter". (3) Although ECG is an old technology that was invented by Einthoven back in 1903, its shine has not been replaced by newer, modern-day technologies. Prof Chia said at the 15th Sukaman Memorial Lecture at the ASEAN Federation of Cardiology meeting in 2014, "although there are many pitfalls in the ECG evaluation of ST elevation myocardial infarction (STEMI), with our current ECG knowledge and expertise coupled with clinical correlation as well as the present availability of cardiac biomarkers, echocardiography, computed tomography and percutaneous coronary angiography, accurate diagnosis today can be achieved in the majority of cases" ${ }^{(4)}$ This lecture took place a decade after his highly successful ninth Antonia Samia lecture on ECG at the 14th Asian Pacific Society of Cardiology Congress in 2004. Prof Chia was also an International Editor of the Journal of Electrocardiology for more than a decade. His insights into ECG reading have helped the interventional cardiologists of today to reduce door-to-balloon time by predicting the correct coronary artery to engage first in cases of inferior STEMI. ${ }^{(5)}$ Even just before his death, he was working on another ECG paper that would soon be published.

\section{MEDICAL EDUCATION}

Every batch of medical students in NUS from 1972 to 2016 would remember being taught by Prof Chia. Before the era of professional beatboxing, the Introduction to Cardiac Examination lecture by Prof Chia was accompanied by his vocal simulations of every conceivable cardiac murmur, which received standing ovations from his students. His facial simulation of pursing his lips would forever emboss in one's mind the image of the fish-mouth appearance of mitral stenosis. For the bedside tutorial, Prof Chia pioneered the auscultation of cardiac murmurs with the 'octopus' teaching stethoscope, to which multiple students could listen at the same time. As an examiner for the final Bachelor of Medicine and Bachelor of Surgery or cardiology exit interviews, the presence of Prof Chia at the station was reassuring, as students were unlikely 
to fail, unless deservingly so. After Prof Chia stepped down as NUH's chief of cardiology in 1999, it became a rite of passage for all cardiology trainees to have his final tutorial a few weeks before their exit examination, which covered the entire span of cardiology. Generations of cardiology trainees are indebted to his generous spirit in teaching and his help in passing their examinations.

\section{LEADERSHIP AND HONOURS}

Apart from his university and clinical responsibilities, Prof Chia was involved in many local and regional societies. Together with the late Dr Tan Ngoh Chuan, he wrote the constitution of and registered the Singapore Cardiac Society in 1973. He was past president of the society four times (1977, 1980, 1983 and 1989) and was founder and past president of the Singapore Hypertension Society (2001) and vice-chairman of the former Singapore National Heart Association (1982). He was council member of the Academy of Medicine Singapore (1981-1985) and Chairman of the Chapter of Physicians (1981), and member of the 17 th and 18th Council of the Singapore Medical Association.

In the realm of clinical cardiology, Prof Chia was peerless. His patients ranged from kings to the common man. He received the following honours for these contributions: Dato Paduka Mahkota Brunei (1984), the Lee Foundation-National Healthcare Group Lifetime Achievement Award (2005), honorary member of the Singapore Medical Association (2008) and the Singapore Cardiac Society Lifetime Achievement Award (2014). For his years of service in the public sector, he was often asked if he could be considered the father of cardiology in Singapore. His humble reply was that "the honour belongs to Charles Toh, but if you must, I could be considered the doyen of cardiology, a respected person who speaks for others".

\section{COURAGE IN ADVERSITY}

At the age of 43 years, Prof Chia was struck with Stage 4 nasopharyngeal carcinoma. Despite knowing the poor prognosis of his condition, he sought treatment in Hong Kong with a new high-dose radiotherapy regimen. In a reversal of the doctor-patient role, he said, "Once you have found a good doctor, trust him fully and do everything he says without question". This philosophy of trusting a colleague to care for him helped him through the darkest days of his life. He suffered many long-term complications from his initial radiation treatment, including pan-hypopituitarism, which he said, with tongue in cheek, contributed to his cherubic look. Over the years, he had multiple health issues, including poor wound healing, intubation for epiglottitis and diplopia from cranial nerve palsies. Each time, Prof Chia overcame the issue and returned to teaching in the department. To overcome his diplopia, which stopped him from driving, Prof Chia taught himself to adjust his glasses with a series of stick-on prisms to correct his vision so that he could see his ECGs. This expertise was previously not available in Singapore, but necessity prompted him to master his situation, and Prof Chia became an expert in the field of diplopia correction.

\section{THE FINAL BATTLE}

Foreshadowing things to come, Prof Chia said in 2006, at the 16th Seah Cheng Siang Memorial Lecture, "Perhaps, as recommended by some experts, the best strategy for all of us is to strive to die young at the latest possible age - not just for ourselves, but for the entire population. The best example of this achievement is the world renowned researcher on cigarette smoking, Sir Richard Doll, who died in 2005 following a short illness, at the age of 92 years. But alas for many of us, this is something that may be difficult to attain."(1)

In November 2017, he had a recurrence of secondary cancer of the tongue. He had already made up his mind that there would be no heroic surgery or measures this time. He said that his heart was at peace and he slept well at night, unlike 35 years before. Tributes from friends, past students and patients arrived from as far as Brazil and Toronto in the form of videos, to reassure the man who had made a difference in their lives. His message to them ten days before his passing was: "In my lifetime, I have two major aims: To lead an honourable life and to have an honourable death. The first has been achieved, with your kind thoughts and prayers. I'm confident that the second will also be achieved".

Ten days later, his wish was fulfilled in the company of his family, whom he loved dearly, with the peace he desired.

A/Prof James Yip

A/Prof Poh Kian Keong

Prof Tan Huay Cheem

National University Heart Centre, Singapore

\section{REFERENCES}

1. Chia BL. 16th Seah Cheng Siang Memorial Lecture-the changing face of cardiology practice, training and research in Singapore. Ann Acad Med Singapore 2006; 35:729-34.

2. Tai ES, Chia BL, Bastian AC, et al. Ministry of Health Clinical Practice Guidelines: Lipids. Singapore Med J 2017; 58:155-66

3. Yan P. Review: Clinical Electrocardiography 4th Edition. Singapore Med J 2016; 57:97.

4. Chia BL. 15th Sukaman Memorial Lecture: ST Segment Elevation: New Electrocardiographic Insights in 2014. ASEAN Heart J 2016; 24:6. eCollection 2016 Oct.

5. Chia BL, Yip JW, Tan HC, Lim YT. Usefulness of ST elevation II/III ratio and ST deviation in lead I for identifying the culprit artery in inferior wall acute myocardial infarction. Am J Cardiol 2000; 86:341-3. 